Article

\title{
A Framework to Assess Fiscal Vulnerability: Empirical Evidence for European Union Countries
}

\author{
Andreea Stoian ${ }^{1}$, Laura Obreja Brașoveanu ${ }^{1, *}$, Iulian Viorel Brașoveanu ${ }^{1}$ and \\ Bogdan Dumitrescu ${ }^{2}$ \\ 1 Department of Finance and CEFIMO, Bucharest University of Economic Studies, 010961 Bucharest, Romania; \\ andreea.stoian@fin.ase.ro (A.S.); iulian.brasoveanu@fin.ase.ro (I.V.B.) \\ 2 Department of Money and Banking and CEFIMO, Bucharest University of Economic Studies, \\ 010961 Bucharest, Romania; bogdan.dumitrescu@fin.ase.ro \\ * Correspondence: laura.brasoveanu@fin.ase.ro
}

Received: 7 June 2018; Accepted: 10 July 2018; Published: 16 July 2018

\begin{abstract}
Following the financial crisis of 2007 and the sovereign debt crisis in 2010 that affected the soundness and reduced the strength of public finance in European countries, there has been a growing interest in developing methodologies to the help assess and signal the vulnerability of fiscal policy. Therefore, the aim of this study is to develop a new framework $(V-L-D)$ to assess fiscal vulnerability. $V$-L-D represents a new methodology on the measurement of fiscal vulnerability that relies on the assumption that vulnerability can occur even during calm times. In comparison with previous methodologies that studied fiscal vulnerability around crisis and fiscal distress times, our framework investigates fiscal vulnerability near fiscal adjustments episodes. Our methodology relies on two distinct indicators: one showing the vulnerabilities indicated by the level of the cyclically adjusted budget balance and distance-to-stability, and one showing the vulnerabilities pointed out through the changes of the cyclically adjusted budget balance and public debt. $V-L-D$ is able to classify fiscal vulnerability into five distinct categories having scores from 0 (no fiscal vulnerability) to 4 (extreme fiscal vulnerability). Using annual data ranging over 1990-2013 for 28 European Union countries, we evidenced 310 episodes of fiscal vulnerability, out of which 128 episodes of low vulnerability, 94 of moderate, 62 of strong, and 26 of extreme fiscal vulnerability. We also found that over 2004-2013, Greece, Portugal, Romania, United Kingdom, Ireland, Spain, and Slovenia were the most fiscally vulnerable countries in the Union. United Kingdom and Greece went through the longest episodes of fiscal vulnerability, counting 12 and 11 consecutive years, respectively. We tested our framework's effectiveness against the Excessive Deficit Procedure. We found that the overall performance is good: $V$-L-D assessed moderate fiscal vulnerability during the procedure, strong fiscal vulnerability in the first year when procedure was initiated, and extreme vulnerability one year before the initiation.
\end{abstract}

Keywords: fiscal policy; budgetary deficit; fiscal sustainability; fiscal vulnerability; primary balance; public debt; European Union

JEL Classification: E62; H12; H6

\section{Introduction}

In recent decades, countries worldwide have faced various and growing challenges. Since the Great Depression in 1929-1933, the role of the government in the economy has been strongly revisited. The liberal paradigm, which advocated the minimalist government's interference, shifted to the welfare state paradigm. Increasing peoples' needs for education, healthcare, social security, and protection against poverty and inequality, and the call for better access to these goods, led to a more prominent role 
of governments in their provision. For instance, the European countries were the first to deliver public pension schemes and social protection through the public system [1]. One significant effect of these developments was the substantial increase in the social public spending, which caused government expenditures to grow. Adema, Fron, and Ladaique [2] showed that for the Organisation for Economic Co-operation and Development (OECD) countries, this increase was 20\% over 1980-2007. Corsetti, Roubini [3], and Alesina [4] warned on the negative effects of rising public social expenditures on fiscal sustainability, even if the generally accepted view on the welfare states is that they are characterized by sizeable budgetary deficits and public debts; Tanzi and Schuknecht [5]

The literature over the last two decades has emphasized once more the large increase in primary deficits and public debt over the past forty years due to financial bailouts, lower government revenues, and stimulus spending (i.e., Ghosh, Kim, Mendoza, Ostry, and Qureshi [6]; Reinhart and Rogoff [7]). It has also shown that the fiscal position in many advanced economies has not significantly changed for the last 30 years and that fiscal policy has been mildly pro-cyclical (i.e., Claeys [8]; Fatas and Mihov [9]; Afonso, Agnello, Furceri, and Sousa [10]). These findings suggest the existence of some vulnerabilities in the fiscal policy, which, unaddressed in the short or medium term, could contribute to a larger deterioration of the fiscal policy condition and lead to fiscal crisis or fiscal distress. Hemming, Kell, and Schimmelpfennig [11] revealed that fiscal vulnerabilities were central in at least six of the eleven cases of crises that they investigated. In the cases of Russia and Ecuador, public sector solvency and liquidity problems culminated in the sovereign debt default. Negotiated restructuring under the shadow of default in the case of Ukraine and Pakistan, and persistent and growing fiscal deficits in Bulgaria and Brazil were central causes, which put so much pressure on national currencies.

The financial crisis in 2007-2008, followed by the sharp economic recession, brought into attention the importance of fiscal policy as a relevant tool to governments' disposal, used to respond to shocks and/or to recover from the crisis. Stiglitz [12] stated that monetary policy measures undertook by United States and the European Union (EU) governments proved to be inefficient, and the probability of a contribution towards sustainable economic growth is low. He argued that there would be a strong need for alternative measures to stimulate the growth and that these measures could stem only out of fiscal policy. Pisani-Ferry [13] also advocated that governments should have stimulated the economy through an expansionary fiscal policy, instead of consolidating for achieving fiscal sustainability in the long run.

Furthermore, the sovereign debt crisis of the European countries led to a comprehensive reform of the fiscal rules in the Union. Although the position of the public finances should have been guarded by the rules established through the Stability and Growth Pact (SGP) adopted in 1997 [14] and amended in 2005 [14], in practice, the fiscal position of many EU countries proved to be very vulnerable in the face of both the financial and the debt crisis. This revealed structural flaws in both the design of the fiscal framework and in the commitment of the national governments for respecting the fiscal rules. The ceilings of $3 \%$ for the headline budgetary deficit and $60 \%$ for public debt proved to be weak in a context of a prolonged economic decline and a positioning in the downturn phase of the economic cycle. It had become very clear that new rules were necessary in order to strengthen the resilience of public finances to shocks and in order to enhance the commitment of policymakers to rules. As a result, the fiscal framework of the EU was significantly amended with the European Semester introduced in 2011 [15], and new treaties were adopted: the package of six legislative measures on economic governance (Six-Pack)—2011 [16]; the Treaty on Stability, Coordination, and Governance in the Economic and Monetary Union (TSCG) -2012 [17]; and the package of two regulations on economic governance (Two-Pack)—2013 [18].

The European Semester [15] also acknowledged the fact that the coordination of fiscal policies in a monetary union is of utmost importance in order to ensure the synchronization of the business cycle of various EU countries. Early scrutiny by the EU institutions of the budgetary plans should contribute to the prevention of the accumulation of vulnerabilities and could promote an enhanced commitment 
of national governments toward respecting the fiscal rules. EU countries that do not follow the recommendations can be fined, and fiscal supervision is now performed at a consolidated level.

The package of six legislative measures on economic governance (Six-Pack) [16] was designed to strengthen the provisions of the amended Stability and Growth Pact [14] by introducing a more effective fine mechanism and, more importantly, a consolidated macroeconomic surveillance. Now, the sanctions are applied through the decision of the European Commission unless they are overruled by a qualified majority of member states votes. In addition, the macroeconomic imbalances procedure is established, defining also the significant deviation from the medium term objective, for which member states should submit a credible plan to correct. Thus, both the corrective arm and the preventive arm of the Stability and Growth Pact were strengthened.

The Treaty on Stability, Coordination, and Governance in the Economic and Monetary Union [14] set explicit limits for the medium term objectives of signatory countries, with a lower allowed limit for the budgetary balance of $-1 \%$ of GDP, only for member states with a public debt significantly below the $60 \%$ of GDP threshold. Moreover, the so called automatic correction mechanisms were introduced, by which a country confronted with a significant deviation from the medium term objective must take corrective actions in a timely manner. The rules had to be enshrined in the national legislation, preferably at the constitutional level, with their observance monitored by national independent fiscal institutions.

Finally, the package of two regulations on economic governance was introduced in 2013 [18] only for euro area countries and envisaged a strengthening of the surveillance mechanism, as countries are obliged to send the initial budgetary plans and the plans for correcting excessive budgetary deficits to the European Commission for scrutiny regarding compliance with the EU fiscal framework discussed above. Thus, the emphasis is put on early detection of fiscal vulnerabilities rather than on ex-post correction of a budgetary imbalance.

The recent reform of the EU fiscal framework over the period 1997-2013 has been designed to limit the vulnerability of public finances to economic shocks and to strengthen the commitment of national governments to fiscal rules and fiscal discipline. The financial and debt crisis clearly showed the vulnerabilities of the public finances in many EU countries and the spillovers that they can generate especially in a monetary union. In theory, the new regulations should diminish the vulnerability of the public finances, but there is no guarantee that they will be effective given also the past track record of EU fiscal rules. Moreover, for non-euro area countries, like the Eastern European countries, the rules are not as tight as for euro-area countries and potentially lead to a more vulnerable fiscal position.

Along with the changes of the supranational and/or national fiscal frameworks, the analytical work, which has been conducted since 2009 by the International Monetary Fund (IMF) and the European Commission (EC), reinforced the importance of assessing fiscal vulnerability and to warn early on the potential fiscal distress. In this light, the aim of this paper is to develop a new framework to assess the fiscal vulnerability of one country. Compared with previous methodologies that studied fiscal vulnerability around crisis and fiscal distress times, our framework investigates fiscal vulnerability near fiscal adjustments episodes. Therefore, our contribution to the literature is that we provide a distinct approach on the measurement of fiscal vulnerability that relies on the assumption that vulnerability can occur even during calm times. The rest of the paper is structured as follows. Section 2 presents the related literature. Section 3 defines the concept of fiscal vulnerability and describes our original framework. Section 4 shows, on one hand, the results of fiscal vulnerability assessment using the proposed methodology and its possible extensions, and, on the other hand, it includes the verification of methodology's effectiveness. Section 5 draws the main concluding remarks of our study. We also note that the processing of some data is shown in tables placed in Supplementary Materials, which will be recalled at the appropriate time in the text. 


\section{Related Literature}

The review of the relevant literature in this field revealed a number of studies, which provided various frameworks to assess fiscal vulnerability. Hemming and Petrie [19] brought an important contribution in this sense, as they pioneered the existing body of research at that time by formulating one explicit definition of fiscal vulnerability. They also discussed the main sources of fiscal vulnerability, and presented a comprehensive list of variables, which could be considered in further evaluation techniques. However, they did not provide any methodological aspects of the assessment.

Rial and Vicente [20] employed a sensitivity analysis in order to study the vulnerability of public debt in the case of Uruguay. The investigation conducted by the two authors is consistent with their own definition of fiscal vulnerability as representing any violation in liquidity and/or solvency requirements due to changes in macroeconomic conditions. The methodology employed is appropriate for an economy like Uruguay, which was confronted with high volatility in its macroeconomic conditions. They began the analysis starting from a baseline scenario and defined additional scenarios assuming that the debt determinants (GDP growth rate, interest and exchange rate) vary by one and two standard deviations.

The macroeconomic developments since 2008, which culminated with the sovereign debt crisis in the EU, have increased the interest in the study of fiscal vulnerability. Thus, the literature has grown over the last years. In this sense, Ghezzi, Keller, and Wynne [21] developed an index of fiscal vulnerability, which incorporates debt tolerance considerations by looking at five components of vulnerability: solvency (basic debt dynamics, i.e., whether the debt ratio is stable or increasing); fiscal financing needs and debt composition; external financing dependence; financial sector health; and institutional strength. The idea is that a judgment as to whether the debt dynamics point to a possible default depends in part on the other factors.

Baldacci, McHugh, and Petrova [22] contributed to the development of a fiscal monitoring framework by employing a fiscal vulnerability index, which measures the fiscal vulnerability on a continuous basis as departure from historical norms defined as 10-year country averages and a fiscal stress index to assess the country's susceptibility to extreme tail events. The fiscal vulnerability index was constructed using basic fiscal variables and variables indicating long term fiscal trends and assets and liabilities management. Each variable is standardized using the 10-year average and the standard deviation for each group of countries (advanced and emerging economies) and then transformed into cumulative normal distribution. The fiscal stress index was computed firstly by defining a fiscal crisis, secondly by assessing the signaling power of each indicator using the standard approach applied in the early warning systems, and finally by calculating the number of indicators exceeding the thresholds. The shortcomings of this methodology are noticed by the authors themselves and concern, on one hand, the meaning of the historical norms and deviations from them in the case of the vulnerability index and, on the other hand, the specific definition of crisis events in the case of the stress index. Later on, Baldacci, Petrova, Belhocine, Dobrescu, and Maazrani [23] conducted a more detailed and extensive investigation on fiscal stress using the same methodology as in a previous study. The contribution of the latest paper is that they built the methodology on the basis of a broader definition of fiscal crisis, which also included the public debt default, as well as the near default events.

BlackRock Investment Institute [24] introduced the BlackRock Sovereign Risk Index for assessing the credit risk of sovereign debt issuers. They used several variables organized into four categories: fiscal space (debt level and structure, demography, default history, etc.); external finance position; financial sector health; and willingness to pay (political and institutional factors). The index was computed using the z-score methodology and weighted. This index proved to be highly correlated with five-year credit default swap (CDS) spreads.

Hayes [25] developed the Barclays Capital Fiscal Vulnerability Index, which was computed using 16 indicators of fiscal vulnerability across 57 countries. To assess fiscal vulnerability, a measure of financial market concerns about a country's debt sustainability was chosen, namely the cost of insuring against a government defaulting on its bonds, as measured by CDS rates. A higher CDS rate indicates 
that investors attach a higher likelihood to a government default, and they took this to indicate a heightened probability of a financial crisis. The choice of vulnerability indicators and the weights given to them in the overall index are determined by their ability to account for cross-country variation in CDS rates. The indicators are grouped under five broad headings: solvency, government financing needs, external financing dependence, financial sector health, and institutional strength, and the composite index is reported as a z-score for each country. In Hayes's view, the z-score is a measure of how far one country's vulnerability is from the cross-country average, and it represents a rather relative measure of vulnerability than an absolute measure. A positive z-score indicates that the country's fiscal resilience is above average, while a negative score indicates below average resilience.

Schaechter [26] developed a more complex toolkit for assessing fiscal vulnerability and risks. They introduced six tools organized by their time horizon: indicators measuring short time pressures included gross financing needs, market-based measures of sovereign risk default (credit default swap and relative asset swap) and a measure of potential spillovers (distress dependence among sovereigns); and indicators assessing medium to long run vulnerabilities comprising a measure of fiscal effort required to stabilize debt (the size of fiscal consolidation required), a measure of assessing the adverse impact of growth and interest shocks and debt trajectory, and a measure of the debt outlook reflecting risks associated with baseline debt projections. For each tool, distinct estimation techniques were employed.

Berti, Salto, and Lequien [27] presented an early warning index of fiscal stress named ' $\mathrm{S} 0$ ', which relies on a non-parametric signals approach. They followed the existing definition of fiscal stress in order to study the key variables' behavior ahead of these episodes. They chose a signaling window and making use of the optimization criterion, they determined the thresholds for fiscal risk for each variable and for the composite indicator. Compared with previous studies using similar methodologies, their original contribution is represented by the introduction of competitiveness-financial variables.

\section{Describing the New Methodological Framework (V-L-D) to Assess Fiscal Vulnerability}

Detecting fiscal vulnerability is rather difficult. The existing literature has provided several frameworks in this sense. The renewed focus of the IMF and the EC has increased the interest in finding new ways of signaling the vulnerability of fiscal policy. In many of the previous studies, we found comprehensive and sophisticated techniques. The contribution of this study is to provide a new framework to assess vulnerability based on a new approach. Much of the relevant work in this field has focused on measuring or signaling fiscal vulnerability around episodes of fiscal crises defined, for example, as situations when public debt was defaulted or restructured, when the governments benefited from an IMF supported program exceeding $100 \%$ of a country's quota, when the inflation rate was excessively high, or when the sovereign bond yields were exceptionally high (Baldacci, McHugh, and Petrova [22]; Baldacci, Petrova, Belhocine, Dobrescu, and Maazrani [23]; Berti, Salto, and Lequien [27]). The aim of this research is to develop a new methodology that is capable of measuring the vulnerabilities in fiscal policy that do not necessarily imply an immediate fiscal stress or crisis. The following parable can illustrate this approach: imagine an individual who is running blood tests on annual basis in order to check the state of his health. The results can indicate a high level of sugar blood. He has not been diagnosed as diabetic yet, he has not collapsed yet, he has not confronted any extreme state of health yet. However, the blood tests point towards a vulnerability. The physician will recommend some treatment and will keep the patient under supervision in order to avoid any further complications. The patient takes the treatment and one year later, he can find that the level of sugar blood decreased significantly and that the vulnerability (threat) passed.

One important step in building such a kind of methodology is to understand the concept of fiscal vulnerability. We reviewed much of the relevant literature on this topic-Furman and Stiglitz [28]; Brixi, Shatalov, and Zlaoui [29]; Hemming and Petrie [19]; Detragiache and Spilimbergo [30]; Allen, Rosenberg, Keller, Setser, and Roubini [31]; Hemming, Kell, and Schimmelpfennig [11]; Rial and Vicente [20]; Daniel, Davis, Fouad, and Van Rijckeghem [32]; Bruglio, Cordina, Farrugia, and Vella [33]; 
Aizenman and Pasricha [34]; Frankel and Saravelos [35]; Baldacci, McHugh, and Petrova [22]; Greene [36]; Hayes [25]; Leiner-Killinger [37]; Jedrzejowicz and Kozinski [38]; and Missale [39]—and found the following points. Fiscal vulnerability can be determined, on one hand, by inherent factors such as the poor size and composition of government revenues and expenditures; poor structure of the public debt; and weak fiscal institutions, budgeting processes, government assets and liabilities management, and so on, which can induce a kind of intrinsic vulnerability in fiscal policy. If these weaknesses are 'nurtured' by the governments over the years, for electoral or political purposes, then the intrinsic vulnerabilities could self-fulfill into a fiscal crisis. On the other hand, there are exogenous factors such as poor economic conditions, financial sector spillovers, demographic, political or environmental changes, and so on, which are not specific to fiscal policy, but could generate exogenous vulnerabilities affecting the size and/or the dynamics of fiscal variables (e.g., the latest financial crisis of 2007-2008 required substantial government aid from the state budget, which led to a significant growth of public debt, exposing fiscal policy to a higher degree of vulnerability).

Analyzing the sources of fiscal vulnerability described by the existing literature-Hemming and Petrie [19], Cottarelli [40], Greene [36]—we concluded that their effects are eventually revealed by the size and/or by the changes of the budget balance and/or of the public debt. Thus, we can define fiscal vulnerability as 'any kind of intrinsic weakness in the existing fiscal policy or exogenous shocks that lead to a significant deterioration in the level and/or dynamics of budget balance and/or public debt that will limit the government's ability to achieve its goals'.

The newly developed framework to assess fiscal vulnerability proposed in this study is consistent with this definition. We built an indicator $\left(V_{i t}\right)$ that comprises two sub-indicators: one measuring the vulnerabilities revealed by the level of two fiscal variables $\left(L_{i t}\right)$ and one quantifying the vulnerabilities showed by their changes over two consecutive years $\left(D_{i t}\right)$. $L$ and $D$ receive scores depending on the size of these indicators compared to certain thresholds. We sum up the scores and the result represents the final measure of fiscal vulnerability (see equation below):

$$
V_{i t}=L_{i t}+D_{i t}
$$

where $i$ is the country assessed and $t$ is time.

In order to compute the indicator of level $\left(L_{i t}\right)$, we use the cyclically adjusted balance $(C A B)$ and the distance-to-stability $(D-S)$. We use the overall budget balance as a leading variable because it includes the interest payments on public debt from previous years and it captures the influence of past deficits on the current fiscal policy. Even if governments make efforts in achieving primary surplus, if the interest payments are sizeable, they will turn the surplus into an overall deficit. Ultimately, governments have to borrow money or adjust the fiscal policy. We decided to use the cyclically adjusted balance because variations in the budget balance can give a misleading picture of the fiscal stance and because an improvement of fiscal balance during the upswings can mask a deterioration in the underlying position of the public finances; Bouthevillain and Quinet [41]. The distance-to-stability indicates the likelihood of current public debt to deviate from its steady state. Consequently, it could exhibit an unstable trajectory on medium term and/or in the long run if governments do not achieve primary surplus or do not consolidate fiscal policy. We compute $D-S$ using the public debt dynamic model, which is detailed in Appendix ??. We can state that fiscal policy is vulnerable when the size of the cyclically adjusted balance is larger than a specific threshold and/or when $D-S$ shows that the current primary balance is lower than the required primary balance for stabilizing the public debt.

The calculation of the indicator of dynamic $\left(D_{i t}\right)$ is based on the changes of the cyclically adjusted balance $(\triangle C A B)$ and of the public debt $(\triangle D e b t)$ for two consecutive years. We decided to take into consideration a period of two consecutive years because we wanted to capture those deteriorations of fiscal variables that led to the decision to pursue the fiscal adjustment. In order to control for the situations when increasing public debt and/or overall deficit can contribute to economic growth, we chose to focus on the changes of the cyclically adjusted balance and of the public debt, both expressed as gross domestic product (GDP) ratios. Raising ratios suggests that $C A B$ and/or Debt 
increase faster than GDP. We assess fiscal policy as being vulnerable when the cumulated changes of cyclically adjusted balance and/or the public debt are larger than a specific threshold.

In order to establish a relevant threshold for both the size of $C A B$ and the changes of $C A B$ and $D e b t$, we analyze the data around fiscal adjustments episodes. We examine the level and the changes of the cyclically adjusted budget balance and of public debt-to-GDP ratios in the year before the fiscal adjustment episode. This approach makes an important distinction between our original methodology and what has been provided by previous studies. We follow Alesina and Ardagna [42] to define the fiscal adjustment as a period of few consecutive years characterized by small improvements in the cyclically adjusted primary balance, which includes at least one year when the improvement was at least 1.5 per cent of GDP or a period of few consecutive years when the average improvement in the cyclically adjusted primary balance is at least 1 per cent of GDP per year.

Using annual data over the period 1990-2013 extracted from AMECO [43] (Our research developed over January 2014-June 2015; we decided to keep the original dataset available as of June 2015 to establish the threshold for the key fiscal variables.) for 28 EU countries, we evidenced 64 episodes of fiscal adjustments (see Table S1). We studied the values for $C A B, \triangle C A B$, and $\triangle D e b t$ one year before the fiscal adjustment and calculated the median (We decided to use the median in order to eliminate the influence of large values recorded for some countries, mostly because of specific circumstances. Ireland, for example, registered a 47 p.p. deterioration in the public debt-to-GDP ratio in 2010 compared with 2008 , and a 20 p.p. deterioration of the $C A B$ compared with the previous year and clearly represents an outlier.) in order to find the thresholds. The following thresholds were established: (i) a deficit of 4.7 p.p. of GDP for the $C A B$; (ii) a deterioration of the $C A B$ by 2.3 p.p. of GDP for two consecutive years; and (iii) an increase of the Debt by 6.1 p.p. of GDP for two consecutive years. In order to assess fiscal vulnerability, we looked for values larger than the median. We also checked the thresholds to see if they are relevant for countries in the Union. In this sense, we calculated the medians of $C A B, \triangle C A B$, and $\triangle D e b t$ for each country and we made comparisons with the thresholds that we found. Figure 1 plots the results in this sense.

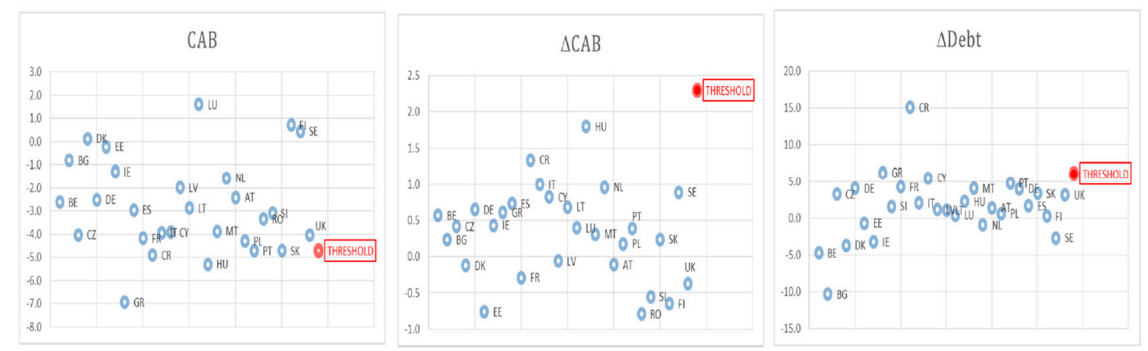

Figure 1. The median of cyclically adjusted balance $(C A B), \triangle C A B$, and $\triangle D e b t$ and thresholds. Source: authors' own calculations.

Analyzing the results, we found out that only Greece $(C A B)$, Croatia ( $C A B$ and $\triangle D e b t)$, and Hungary $(C A B)$ lie outside the thresholds. However, we do not consider these cases as problems umpiring the methodology because of the following reasons. Croatia reported only three observations; for 2011, 2012, and 2013. In the case of Greece, the country specific median for $C A B$ indicates a deficit larger than the threshold by 1.4 p.p. However, a threshold for the cyclically adjusted balance of $-4.7 \%$ of GDP would be more prudential for Greece. We keep the same argumentation for Hungary's case, for which we found a country specific median for $C A B$ of $-5.3 \%$ of GDP.

The indicator of level $\left(L_{i t}\right)$ assessing the vulnerability of one country $(i)$ at time $t$ showed by the size of the cyclically adjusted balance and by the distance-to-stability takes the following values:

$$
\begin{gathered}
L_{i t}=2, \text { if } C A B_{i t} \leq-4.7 \text { percent of GDP, and }(D-S)_{i t}=1, \\
L_{i t}=1, \text { if } C A B_{i t} \leq-4.7 \text { percent of GDP, or }(D-S)_{i t}=1, \\
L_{i t}=0, \text { if } C A B_{i t}>-4.7 \text { percent of GDP, and }(D-S)_{i t}=0,
\end{gathered}
$$


The indicator of changes $\left(D_{i t}\right)$ evaluating the vulnerability of one country $(i)$ at time $y$ revealed by the changes in $C A B$ and in the public debt-to-GDP ratios for two consecutive years $(k)$ takes the following values:

$$
\begin{gathered}
D_{i t}=2, \text { if } \sum_{k=1}^{t=2} \Delta C A B_{k i} \leq-2.3 \text { p.p., and } \sum_{k=1}^{t=2} \Delta D e b t_{k i} \geq 6.1 \text { p.p., } \\
D_{i t}=1 \text {, if } \sum_{k=1}^{t=2} \Delta C A B_{k i} \leq-2.3 \text { p.p., or } \sum_{k=1}^{t=2} \Delta D e b t_{k i} \geq 6.1 \text { p.p., } \\
D_{i t}=0, \text { if } \sum_{k=1}^{t=2} \Delta C A B_{k i}>-2.3 \text { p.p., and } \sum_{k=1}^{t=2} \Delta D e b t_{k i}<6.1 \text { p.p., }
\end{gathered}
$$

Finally, using $V$ - $L-D$ framework, five categories of fiscal vulnerability $\left(V_{i i}\right)$ can be established for one country (i) at time $t$ as in (4):

$$
\begin{aligned}
& V_{i t}=4 \text {, indicating extreme fiscal vulnerability, when } L_{i t}=2 \text { and } D_{i t}=2 \\
& V_{i t}=3 \text {, indicating strong fiscal vulnerability, when } L_{i t}=2 \text { and } D_{i t}=1 \text {, or } L_{i t}=1 \text { and } D_{i t}=2 \\
& V_{i t}=2 \text {, indicating moderate fiscal vulnerability, when } L_{i t}=1 \text { and } D_{i t}=1 \\
& V_{i t}=1 \text {, indicating low fiscal vulnerability, when } L_{i t}=1 \text { and } D_{i t}=0 \text {, or } L_{i t}=0 \text { and } D_{i t}=1 \\
& V_{i t}=0 \text {, indicating no fiscal vulnerability, when } L_{i t}=0 \text { and } D_{i t}=0
\end{aligned}
$$

For instance, when $V-L-D$ indicates extreme fiscal vulnerability, it implies that both the level and changes of the leading indicators show vulnerabilities in fiscal policy. The cyclically adjusted budget has a deficit of at least 4.7 percent of GDP, the distance-to-stability indicates a departure of the public debt dynamics from its stable path, and the changes of the cyclically adjusted budget and of the public debt reveal a significant increase in the last two years. When $V_{i t}$ is zero, the situation corresponds with the state of non-vulnerability. When $V_{i t}$ takes 3,2, or 1, both and/or only one of the indicators $\left(L_{i t}\right.$ or $D_{i t}$ ) show vulnerabilities in fiscal policy. The results and further indicators that can be developed with the use of $V-L-D$ in order to assess fiscal vulnerability over a time frame are discussed in the section below.

\section{The Usefulness and the Effectiveness of the New Methodological Framework (V-L-D)}

In this part of the paper, we aim, on one hand, to present the usefulness of the proposed methodology and its further extensions (Section 4.1), and, on the other hand, we want to test the quality of our methodology in order to check its reliability (Section 4.2). First, we show how the newly proposed methodology can be used in order to evaluate fiscal vulnerability for EU member states (Section 4.1.1). Then, we show various extensions that can be used to further assess the vulnerability of one country's fiscal policy (Section 4.1.2). In the end, we test the quality of the proposed methodology by checking its robustness against the excessive deficit procedure.

\subsection{Results and Further Extensions of the Proposed Methodology (V-L-D)}

\subsubsection{Fiscal Vulnerability Assessment Using V-L-D}

We employed the $V-L-D$ framework to assess fiscal vulnerability for $28 \mathrm{EU}$ countries using data ranging from 1990 to 2013 . Over this period, the total number of observations was 516. $V-L-D$ evidenced 310 episodes (years) of fiscal vulnerability, out of which 26 episodes of extreme vulnerability, 62 episodes of strong vulnerability, 94 episodes of moderate vulnerability, and 128 episodes of low vulnerability were observed (see Table S2). For the rest of 206 observations, $V-L-D$ detected no fiscal vulnerability.

Examining the total value of fiscal vulnerability over time, we can observe that in the years following the financial crisis in 2007, the EU had to tackle the largest magnitude of fiscal vulnerability (see Figure 2).

If we study the magnitude of fiscal vulnerability in relation with the main regulations introduced by the European Commission (the Treaty of Maastricht-1993; SGP_1997; Six-Pack—2011; Fiscal compact and Two-Pack-2013), which were designed to maintain the soundness and strength of 
public finances in the Union, we can observe that the constraints imposed during the 1990s did not prevent the fiscal crisis of 2009. The enforcement of the Six-Pack in 2011, and of the subsequent laws, which amended the original SGP, reduced the degree of fiscal vulnerability, but it has not reached the level registered before the crisis yet.

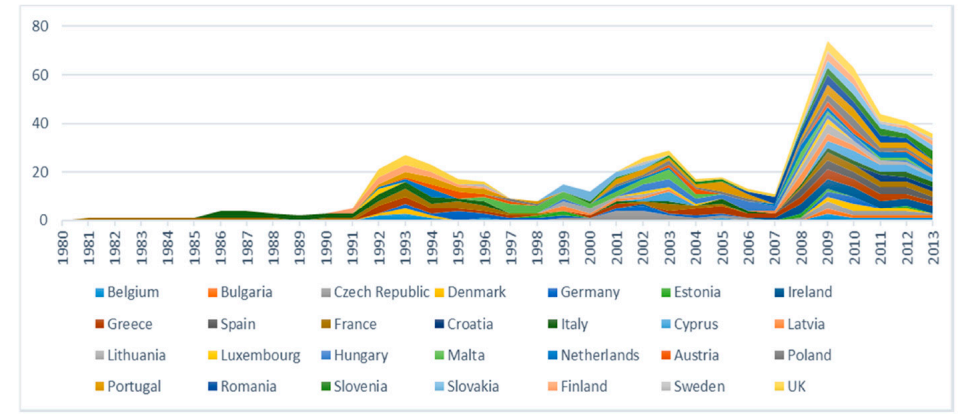

Figure 2. Fiscal Vulnerability across the European Union (EU), 1990-2013. Source: authors' own calculations. Note: fiscal vulnerability can vary from 0 (min.) to 136 (max.) points.

If we focus on the period of economic and debt crisis in the EU (2009-2012) (for Croatia, we had date available starting in 2011; for 2007-2010, we made no calculations for Croatia), we can observe how the degree of fiscal vulnerability increased over time, and which were the most affected countries in the Union (see Figure 3).
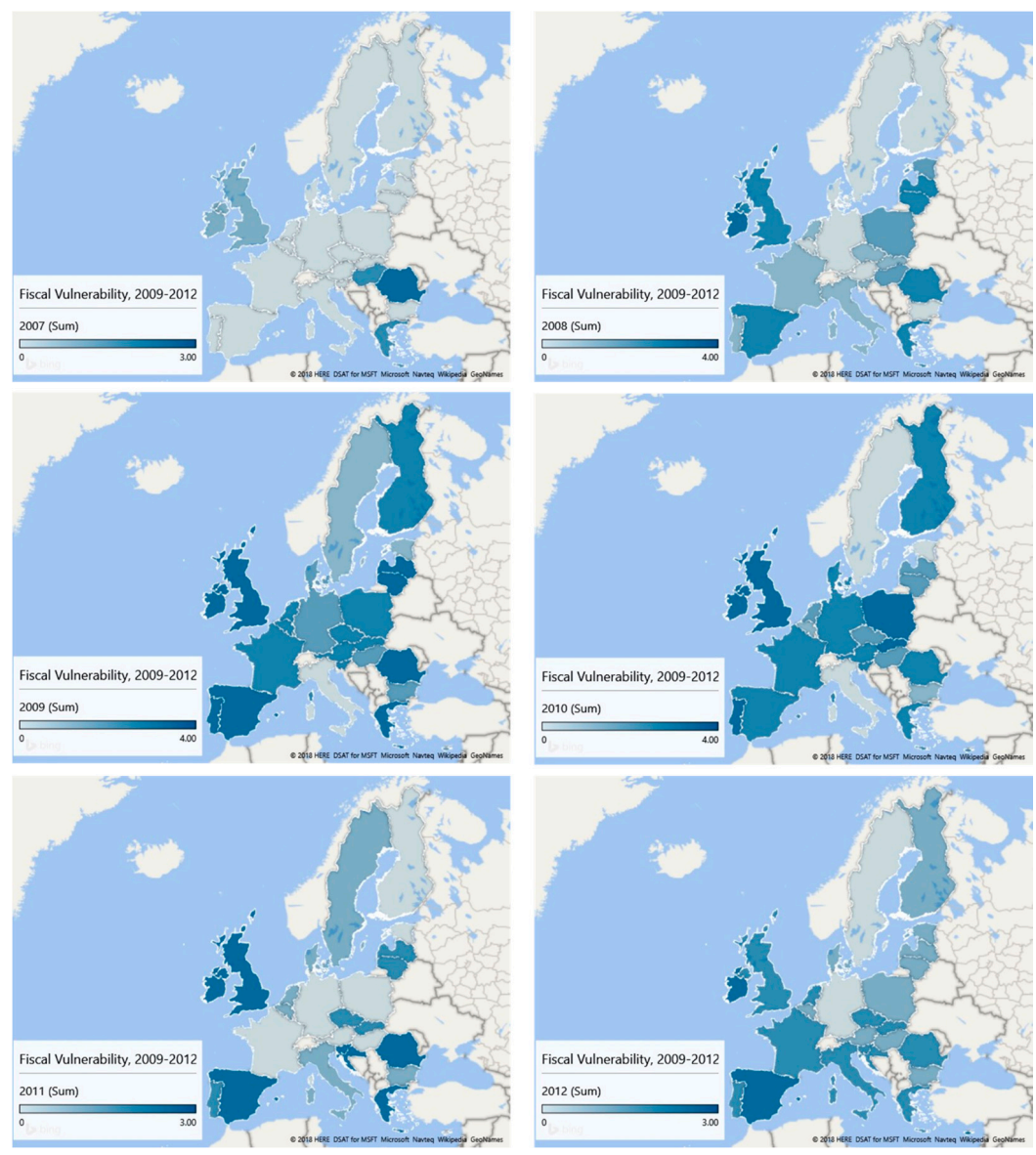

Figure 3. Fiscal Vulnerability in the EU during the economic and debt crisis. Source: authors' own calculations. 
In 2007, at the beginning of the crisis, the $V$-L-D framework indicated that Romania had the most vulnerable fiscal policy in the EU, with a score of 3, which corresponds to strong fiscal vulnerability. Although Romania joined the EU in 2007, by the end of that year, the country reached a cyclically adjusted deficit of 4.98 percent of GDP and an overall budget deficit close to 3 percent of GDP. Romania's public debt-to-GDP ratio was 12 percent of GDP, much lower than the $60 \%$ ceiling. However, the distance-to-stability indicated a primary balance of 0.74 percent of GDP larger than the current one to keep the public debt on a stable path. The effective primary deficit was 2.20 percent of GDP. The effect was that two years later, in 2009, Romania doubled its public debt-to-GDP ratio. The changes in the cyclically adjusted balance in two consecutive years also showed a gradually increase in the deficit. Hungary and Greece scored 2, which corresponds to a state of moderate fiscal vulnerability. In the case of Hungary, the vulnerability was detected by $L$. The cyclically adjusted balanced reached a deficit of 6.63 percent of GDP, while the overall deficit was 5.12 percent of GDP. The distance-to-stability also showed a gap of 1.61 percent of GDP between the required primary balance and the current one. In 2007, Hungary had already exceeded the $60 \%$ debt ratio and public debt continued to increase in the subsequent years. Greece's moderate vulnerability was detected by the level and the changes in the cyclically adjusted balance. The adjusted deficit touched 8.01 percent of GDP after gradually increase in the previous years. Even if Greece recorded at that time a public debt-to-GDP ratio exceeding 100 percent of GDP, the distance-to-stability indicated that the current primary balance was larger than the required one. This result confirmed Greece's efforts to stabilize or to reduce the debt ratio. Ireland, Latvia, the Netherlands, and the United Kingdom were countries that scored 1, corresponding to a state of low fiscal vulnerability. For the rest of the countries, $V-L-D$ indicated no fiscal vulnerability.

In 2008, the degree of fiscal vulnerability increased throughout the Union. Romania kept its score of 3 as in the previous year. The vulnerability was reflected in the size and in the changes in the cyclically adjusted budget and in distance-to-stability, showing once again an unstable path of public debt. Hungary maintained its moderate fiscal vulnerability. Greece increased its vulnerability from moderate to strong as a result of an unstable dynamic of the debt ratio. The United Kingdom changed its fiscal vulnerability condition from low to strong, evidenced by large cyclically adjusted deficit and unstable dynamics of public debt. Ireland and Latvia experienced a strong downturn of their fiscal vulnerability, which deteriorated from low to extreme. Spain, Lithuania, and Malta's fiscal policies were affected by the crisis and their condition worsened from no vulnerability to strong vulnerability. Poland and Estonia's fiscal vulnerability turned to moderate, while Czech Republic, France, Italy, Luxembourg, the Netherlands, Portugal, Slovakia, and Slovenia still had a low fiscal vulnerability. For Belgium, Bulgaria, Denmark, Germany, Cyprus, Austria, Finland, and Sweden, the V-L-D did not detect any fiscal policy vulnerability.

The peak of fiscal vulnerability in the European Union was reached in 2009: seven countries (Ireland, Greece, Spain, Lithuania, Portugal, Romania, and the United Kingdom) were in a state of extreme fiscal vulnerability; nine states (Belgium, the Czech Republic, France, Cyprus, Latvia, Poland, Slovakia, Slovenia, and Finland) were assessed as facing strong fiscal vulnerability; eight economies (Bulgaria, Denmark, Germany, Italy, Luxembourg, Hungary, the Netherlands, and Austria) were assessed as having a moderate fiscal vulnerability; and three countries (Estonia, Malta, and Sweden) had low fiscal vulnerability. More than half of the EU countries were assessed as being strong or extremely vulnerable.

In 2010, fiscal vulnerability in EU slightly decreased. There were six countries for which $V$-L-D measured extreme fiscal vulnerability; fiscal vulnerability declined in the cases of Cyprus, Poland, and Slovakia, while Ireland, Portugal, and the United Kingdom maintained their vulnerability state as in previous year. Fiscal policy in eight states was strongly vulnerable. For Denmark and Germany, the score increased from 2 (moderate vulnerability) to 3 (strong vulnerability); for Greece, Spain, and Romania the score declined from 4 (extreme fiscal vulnerability) to 3 (strong fiscal vulnerability); while France, Slovenia, and Finland maintained their previous condition of strong fiscal vulnerability. Six countries maintained their fiscal condition or improved it to moderate vulnerability (the Czech 
Republic, Italy, Latvia, Lithuania, Hungary, and Austria). Many of the countries improved their fiscal conditions: Belgium, Bulgaria, and the Netherlands upgraded to low fiscal vulnerability, while Estonia, Luxembourg, Malta, and Sweden advanced to non-vulnerable fiscal policies.

In 2011, the number of countries with non-vulnerable fiscal policy or moderate fiscal vulnerability increased to thirteen. We did not measure any extreme fiscal vulnerability for any country in the Union. There were still eight countries with strong fiscal vulnerability, but even so, most of them maintained their previous conditions or progressed like Cyprus and the United Kingdom. The rest of the countries were assessed as having moderate fiscal vulnerability.

In 2012, there were only three countries that were assessed as strongly vulnerable: Ireland, Spain, and Cyprus. For the rest of the EU countries, $V-L-D$ measured non-vulnerability to moderate fiscal vulnerability. Greece significantly decreased its cyclically adjusted deficit.

\subsubsection{Extensions of the V-L-D Methodology}

Starting from the proposed methodology, we can develop various extensions that help us evaluate fiscal vulnerability from multiple perspectives. Thus, we can assess the total fiscal vulnerability throughout the analyzed period, the average fiscal vulnerability adjusted for the number of years when fiscal policy had a certain degree of vulnerability, the length of fiscal vulnerability episodes, and 10-year fiscal vulnerability in order to make more relevant comparisons across countries over the same period of time.

\section{Total Fiscal Vulnerability Score}

In order to measure fiscal vulnerability of one country $(i)$ for a certain period, we can calculate the total fiscal vulnerability score $\left(T F V S_{i}\right)$ as in Equation (5) below:

$$
\operatorname{TFVS}_{i}=\sum_{t=1}^{n} V_{i t}
$$

where $i$ is the assessed country, $n$ is the number of years (episodes) of fiscal vulnerability, and $V_{i t}$ is the score for fiscal vulnerability for country $i$ at time $t$. Table S3 reports the results for TFVS for the $28 \mathrm{EU}$ countries over 1990-2013.

We can use the quartiles of TFVS to rank the countries and to determine which were the least and most vulnerable countries in EU over 1990-2013. The quartiles are: $Q_{T F V S 1}=15.57 ; Q_{\text {TFVS2 }}=21$; $Q_{T F V S 3}=25.25$. Based on these values, we can assess countries as being:

$$
\begin{aligned}
& \text { The least vulnerable, if } T_{F V S} \leq Q_{T F V S 1} \\
& \text { Moderately vulnerable, if } Q_{T F V S 1}<T F V S_{i} \leq Q_{T F V S 2} \\
& \text { Strongly vulnerable, if } Q_{T F V S 2}<T F V S_{i} \leq Q_{T F V S 3} \\
& \text { The most vulnerable, if } T F V S_{i}>Q_{T F V S 3}
\end{aligned}
$$

Figure 4 plots the distribution of the countries according to their corresponding quartile. We use the colors system in order to mark the countries in correspondence with their fiscal vulnerability. The green indicates the countries that were the least vulnerable, the yellow illustrates moderately vulnerable countries, the orange represents strongly vulnerable countries, and the red shows the most vulnerable countries in the EU.

The Czech Republic, Greece, France, Italy, Malta, Portugal, and the United Kingdom were countries that recorded the largest scores and were placed in the upper quartile. This group represents the most vulnerable countries over the period under examination. On the opposite side, Belgium, Bulgaria, Croatia, Denmark, Estonia, Luxembourg, and Sweden lie in the lower quartile, representing the least vulnerable countries in the Union. Austria, Cyprus, Latvia, Lithuania, Spain, and Romania are situated in the second quartile and they were assessed as moderately vulnerable, while Germany, Ireland, Hungary, the Netherlands, Poland, Slovakia, Slovenia, and Finland were strongly vulnerable. 


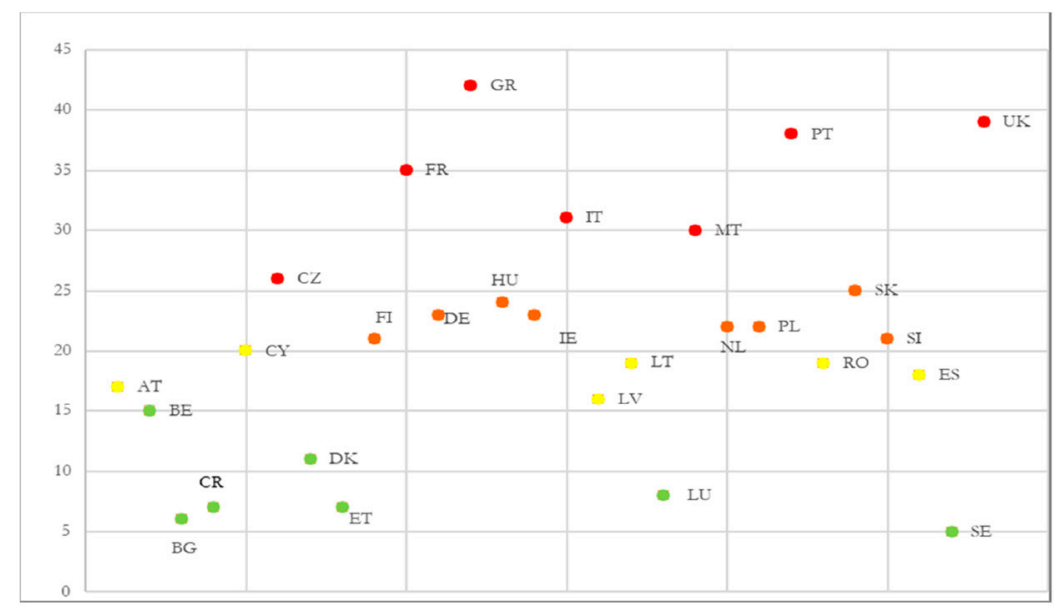

Figure 4. Total fiscal vulnerability score, 1990-2013. Source: authors' own calculations. Legends: green = less vulnerable; yellow = moderately vulnerable; orange = strongly vulnerable; red = the most vulnerable countries in the EU. Note: the total fiscal vulnerability score can vary from 0 ( $\mathrm{min}$.) to 56 (max.) points.

Figure 5 illustrates the relationship between the $T F V S_{i}$, on vertical axis, and the number of years (episodes) of fiscal vulnerability $\left(n_{i}\right)$, on horizontal axis (see Table S3). The colored lines represent the quartiles reported above. We keep the same colors system code as previously mentioned.

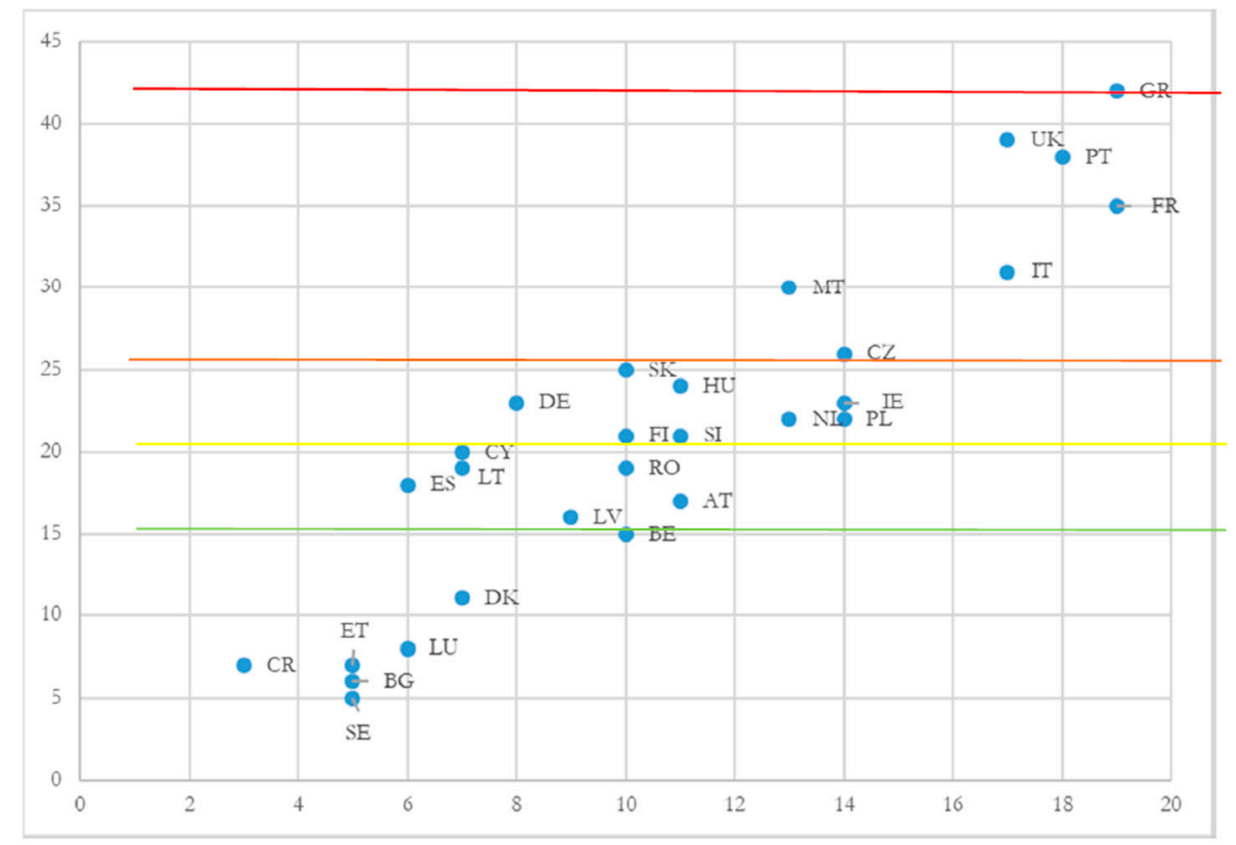

Figure 5. The number of years of fiscal vulnerability vs. TFVS, 1990-2013. Source: authors' own calculations. Note: the total fiscal vulnerability score can vary from 0 (min.) to 56 (max.) points.

We can observe that the least vulnerable countries also experienced a reduced number of fiscal vulnerability episodes. The most vulnerable countries went through a larger number of fiscal vulnerability episodes. 
The Weighted Average Fiscal Vulnerability

Another way to evaluate fiscal vulnerability of one country (i) over a certain period is to calculate the weighted average fiscal vulnerability $\left(W A F V_{i}\right)$. Equation (7) describes its calculation:

$$
W A F V_{i}=\sum_{t=1}^{n} w_{i t} \cdot V_{i t}
$$

where $w_{i t}$ are the weights for a country $(i)$ representing the number of years $(t)$ characterized by a certain amount of fiscal vulnerability (from 0 to 4 ) in the total number of fiscal vulnerability episodes $(n) ; V_{i t}$ is fiscal vulnerability of one country (i) at time $t$, as described in Equation (4).

In order to decide which country is the most vulnerable, we can rank the countries depending on WAFV quartiles: $Q_{W A F V 1}=1.6 ; Q_{W A F V 2}=1.9 ; Q_{W A F V 3}=2.3$. Then, we can assess a country as being:

The least vulnerable, if $W A F V_{i} \leq Q_{W A F V 1}$,

Moderately vulnerable, if $Q_{W A F V 1}<W A F V_{i} \leq Q_{W A F V 2}$,

Strongly vulnerable, if $Q_{\mathrm{WAFV} 2}<W A F V_{i} \leq Q_{\mathrm{WAFV}}$,

The most vulnerable, if $W A F V_{i}>Q_{W A F V}$

Figure 6 depicts the weighted average fiscal vulnerability across the countries in the EU.

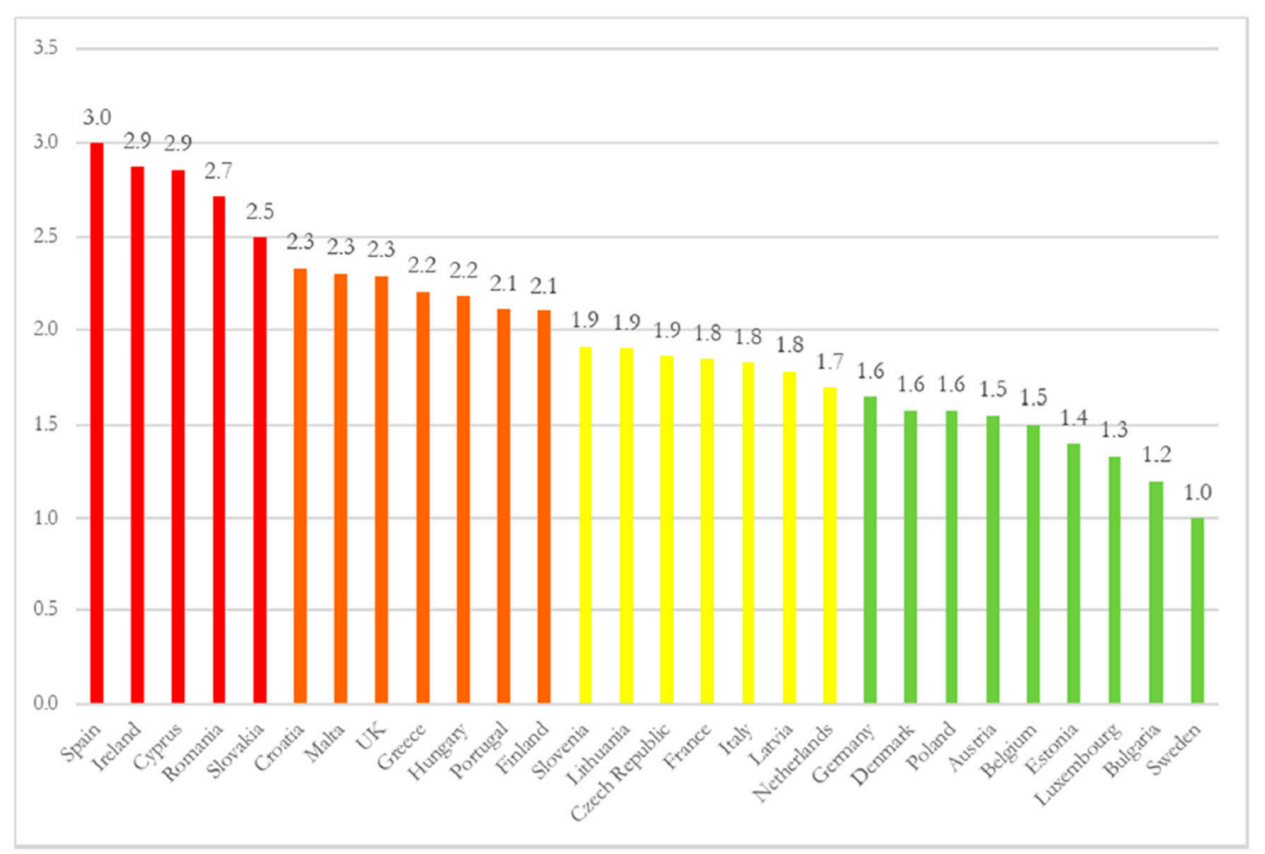

Figure 6. The weighted average fiscal vulnerability across EU countries, 1990-2013. Source: authors' own calculations.

We can observe that over the period 1990-2103, Spain, Ireland, Cyprus, Romania, and Slovakia were the most vulnerable countries, while Germany, Denmark, Poland, Austria, Belgium, Estonia, Luxembourg, Bulgaria, and Sweden were the least vulnerable countries in the EU. The remaining $50 \%$ of the EU countries were assessed as being moderately or strongly vulnerable as they were placed in the second and the third quartiles.

The Length of Fiscal Vulnerability Episodes

We can also study the longest episode of fiscal vulnerability $\left(T_{i}\right)$ for each EU country $(i)$. In this sense, we count the number of consecutive years in which fiscal policy was vulnerable, irrespective 
of its degree. Then, we can establish the corresponding TFVS and WAFV. Table S4 summarizes the results in this sense.

We can note that the United Kingdom and Greece had the longest episodes of vulnerability, which totaled 12 and, respectively, 11 consecutive years. The episodes spanned over 2002-2013 for the United Kingdom and over 2003-2013 for Greece. The shortest fiscal vulnerability episode was reported for Sweden and lasted just one year. We must note that Sweden totaled five distinct episodes of one year. Poland and Portugal also experienced two distinct episodes of vulnerability of six years each.

We calculate the quartiles for the episodes' lengths and for the corresponding TFVS and WAFV. Table S6 reports the results. Examining the quartiles, we found the shortest episodes of fiscal vulnerability in the cases of Belgium, Bulgaria, Luxembourg, and Sweden. The episodes lasted between one and five consecutive years and they were combined with the lowest TFVS and WAFV. Finland went through a six-year episode of fiscal vulnerability of a moderate size. Italy faced a seven-year episode of strong fiscal vulnerability. Malta is one of the countries that was subject to one of the longest episodes of fiscal vulnerability and of the highest TFVS and WAFV. The rest of countries were placed in different corresponding quartiles. For instance, Cyprus was situated in the lower quartile from the length perspective, but TFVS and WAFV place the country in the upper quartile. These results might suggest that the country confronted high fiscal vulnerability over a short period. Germany had a seven-year episode in the third quartile of length, which corresponds to the second TFVS quartile and to the first WAFV quartile. This might indicate that although Germany experienced a larger number of years in which fiscal policy was vulnerable, the fiscal vulnerability varied from low to moderate. We also observed for many advanced economies, such as Germany, France, Italy, Austria, and Finland, the longest fiscal vulnerability episodes took place in the 1990s, much earlier than the recent economic crisis. During the economic crisis, these countries did not experience extreme fiscal vulnerability, only a strong one. These findings suggest that the advanced economies had developed proper fiscal tools that made them much more resilient during a crisis than the rest of the EU countries, and especially than the emerging ones.

The 10-Year Fiscal Vulnerability Score

Taking into consideration that over 1990-2013, the number of observations was not similar for all analyzed countries and that it could influence the results, we decided to narrow our dataset to a sample of ten years over 2004-2013. For this time range, we have 10 observations for all EU countries, excepting Croatia.

Table S6 reports the results for TFVS, the total number of years (episodes) of fiscal vulnerability $(N)$, and for WAFV over 10 years. We calculate the corresponding quartiles $\left(q_{i}\right)$ for each indicator. Using the quartiles, we give scores from 1 to 4 as in the equation below:

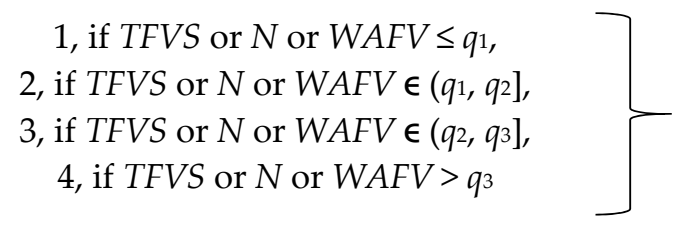

We sum up the scores and we calculate the 10-year fiscal vulnerability score $\left(F V S_{10}\right)$. We rank the countries depending on their $F V S_{10}$ as being:

The least vulnerable, if $F V S_{10} \leq Q_{1}$,

Moderately vulnerable, if $F V S_{10} \in\left(Q_{1}, Q_{2}\right]$,

Strongly vulnerable, if $F V S_{10} \in\left(Q_{2}, Q_{3}\right]$,

The most vulnerable, if $F V S_{10}>Q_{3}$ 
Figure 7 illustrates the 10-year fiscal vulnerability scores over 2004-2013.

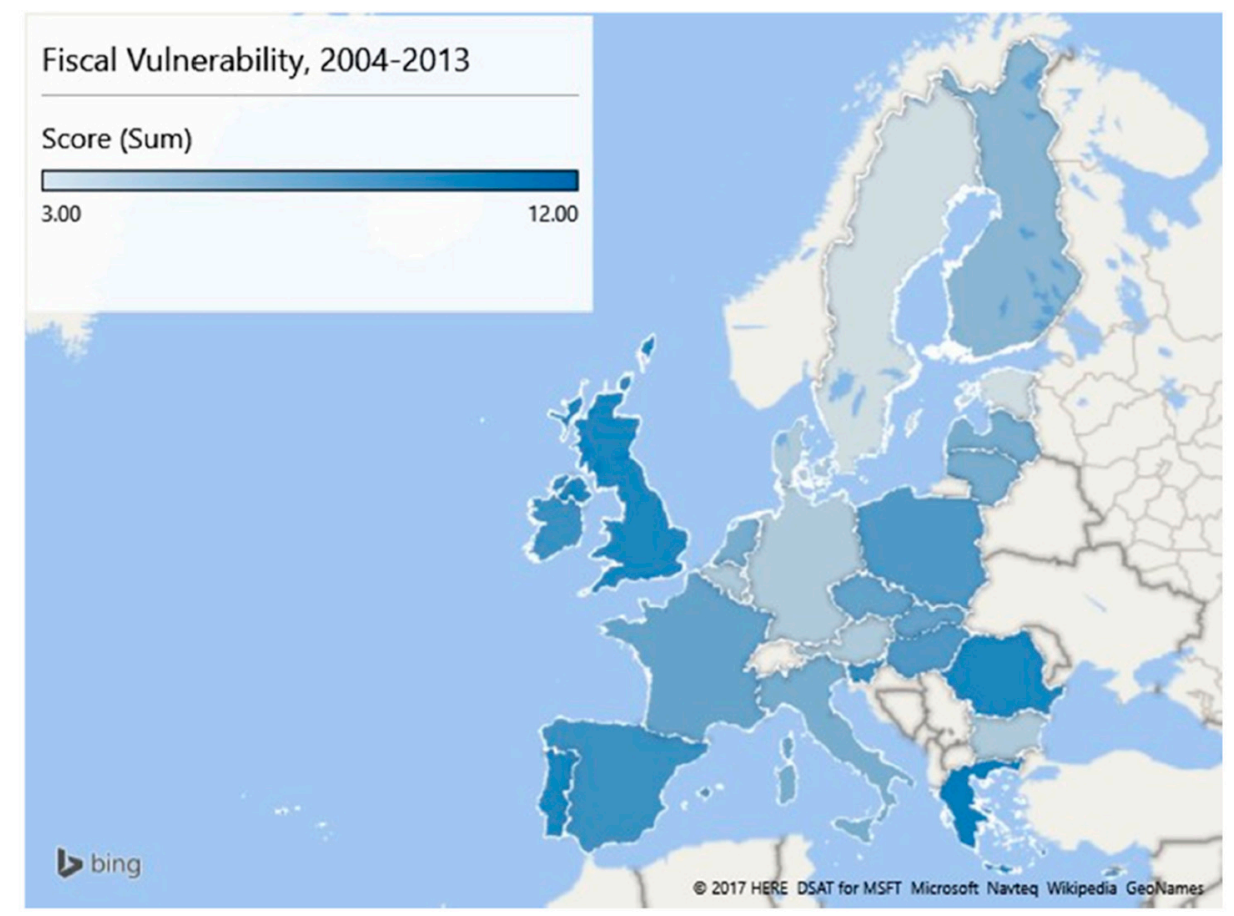

Figure 7. Ten-year fiscal vulnerability score, 2004-2013. Source: authors' own calculations.

We can observe that over 2004-2013, the most vulnerable countries were Greece, Portugal, Romania, United Kingdom, Ireland, Spain, and Slovenia, which belong to the upper quartile of $F V S_{10}$. Belgium, Bulgaria, Denmark, Germany, Malta, Austria, Estonia, Luxembourg, and Sweden were the least vulnerable countries in the Union. The rest of countries were being assessed as moderately or strongly vulnerable. We believe that the countries placed in the upper quartile of the $F V S_{10}$ are countries that have faced several intrinsic or extrinsic fiscal vulnerabilities that which made them more vulnerable and less resilient to a fiscal shock. For instance, Romania was one of the fastest growing economies among the former communist countries. Its consumption-based growth mainly stimulated the imports, while the domestic supply stayed behind. Although Romania has a population of 19 million inhabitants, being one of the largest countries in the Union, its total receipts from taxes and social contributions averaged only $28 \%$ of GDP that places the country on last place in the EU. Greece, Portugal, Ireland, and Spain were known for their growing debt and economic vulnerability in the early 1990s, which made them unable to refinance their government debt or to bail-out the banking system during the economic crisis.

\subsection{The Effectiveness of the Proposed Methodology (V-L-D)}

In order to investigate, verify, and validate the quality of our methodology, we can use the Excessive Deficit Procedure (EDP) as a benchmark to test against. EDP underpins the corrective arm of the EU's SGP, which lays down how countries should take corrective actions in the event that their public debt or budget deficit is considered excessive as defined by the two public finances related convergence criteria. If the norms are not met, the EDP is launched. Countries under the procedure are given a deadline of three to six months (depending of the seriousness of vulnerability) to comply with the recommendations that provide them with a solid path for addressing their excessive deficit. After the deadline has passed, countries' fiscal conditions are reassessed and a decision is made to either put the procedure on hold or step it up if the member states have not taken the effective actions. Taking into consideration the way the procedure has been built, it has operated and it has 
been implemented, we assume that the fiscal policy of a country under EDP is vulnerable, otherwise the procedure would not had been initiated. Therefore, EDP represents a benchmark against which we can examine $V-L-D$ effectiveness in assessing fiscal vulnerability. We use the EC's reports in order to establish the countries and the periods when EDP was introduced. We examine 25 EU countries (we dropped Croatia, which entered under the EDP in 2013, Estonia and Sweden, which were not under EDP during the examined period) over a period ranging from 2002 to 2013 . We found a total of 174 observations when EDP was instituted. Table $\mathrm{S} 7$ reports the data in this sense.

In order to examine the effectiveness of our methodology, we follow Kaminsky, Lizondo, and Reinhart's [44] approach, and we test $V-L-D$ 's performance in terms of the following matrix, presented in Table 1.

Table 1. Testing the $V-L-D$ performance versus EDP.

\begin{tabular}{ccc}
\hline & \multicolumn{2}{c}{ TRUE STATE } \\
\hline State & $\begin{array}{c}\text { EDP Is Introduced } \\
\text { (Fiscal Policy Is Vulnerable) }\end{array}$ & $\begin{array}{c}\text { EDP Is Not Introduced } \\
\text { (Fiscal Policy Is Not Vulnerable) }\end{array}$ \\
\hline$V-L-D$ indicates fiscal vulnerability & $\mathrm{A}$ & $\mathrm{B}$ \\
$V-L-D$ indicates no fiscal vulnerability & $\mathrm{C}$ & $\mathrm{D}$ \\
\hline
\end{tabular}

In this matrix, A represents the number of observations when the EDP was initiated and the $V-L-D$ assessment was 'good' when it indicated fiscal vulnerability, regardless of its size; B represents the number of observations when countries were not under $E D P$, but $V-L-D$ made a 'bad' evaluation, in the sense that it assessed fiscal vulnerability when it was not the case; $C$ represents the number of observations when countries were under $E D P$, but $V-L-D$ failed in making a 'good' assessment, and evaluated fiscal policy as not being vulnerable; $\mathbf{D}$ represents the number of observations when countries were not under EDP and $V-L-D$ correctly evaluated the its state and the assessment was 'good'.

According to Kaminsky, Lizondo, and Reinhart [44], a perfect methodology would produce observations only in A and D cells. $V_{i t}$ would be different from zero each time the EDP is initiated (A $>0$, $C=0)$ and would equal zero when there is no procedure introduced $(B=0, D>0)$. We use the matrix as a helpful reference to assess how close or far $V-L-D$ was from the perfect profile. The authors suggested the calculation of some ratios used to establish methodology's performance: (i) the percentage of 'good' assessments as the ratio between the number of observations when $V-L-D$ confirmed the fiscal vulnerability and the total number of observations when fiscal policy was vulnerable as indicated by the initiation of the $\operatorname{EDP}(A /(A+C))$; (ii) the percentage of 'bad' assessments as the ratio between the number of observations when $V-L-D$ failed in measuring no fiscal vulnerability and the total number of observations when fiscal policy was not vulnerable $(B /(B+D))$; (iii) the so-called 'noisiness' of the methodology as the ratio between the 'good' and the 'bad' assessments, which indicates $V-L-D$ 's ability to make good measurements and to avoid the false ones $([B /(B+D)] /[A /(A+C)])$. The 'noisiness' ratio can be used to decide if the methodology performs well or not. If the ratio is larger than 1 , this suggests that the methodology introduces excessive noise and its effectiveness is reduced.

At first, we test the $V-L-D$ performance against the EDP irrespective of the degree of fiscal vulnerability measured by our methodology. Table S8 summarizes the results in this sense. We can see that the number of observations when $V-L-D$ performed well was 138 , which represents 71 percent of total number of fiscal vulnerability episodes indicated by the EDP (174). The number of observations when $V$-L-D measured no fiscal vulnerability is 60 , representing 61 percent of the total number of observations when fiscal policy was not vulnerable, as shown by the non-initiation of an EDP (98). The number of observations when $V-L-D$ provided false assessments ( $B$ and $C$ ) is smaller than the number of observations when the methodology assessed well. The ratio of 'good' assessments is 79 percent compared with 39 percent for the ratio of 'bad' assessments. The 'noisiness' ratio is 
0.49 smaller than unity. Based on these results, we can state that $V$ - $L-D$ performs well when it assesses fiscal vulnerability for EU countries, regardless of the size of fiscal vulnerability.

Further, we want to examine how $V$ - $L-D$ performs when taking into account the size of fiscal vulnerability. We apply the same methodology for each category of fiscal vulnerability. Table S8 shows the results. We can observe that when $V-L-D$ evaluated fiscal vulnerability as moderate or extreme, the degree of noisiness was lower than in the cases when $V-L-D$ assessed fiscal vulnerability as low or strong.

Then, we test $V-L-D$ 's effectiveness in the first year during which EDP was initiated. We have 41 observations for $25 \mathrm{EU}$ countries in EDP. Table S9 reports the results. The overall methodology's performance is good, considering that the 'noisiness' ratio was below unity. When $V-L-D$ assessed fiscal vulnerability as extreme or strong, the 'noisiness' ratio was the lowest.

Finally, we examine our methodology's performance one year before the EDP begins. We have 33 observations and Table S10 summarizes the results. The overall methodology's effectiveness is good and when $V-L-D$ evaluated fiscal vulnerability as strong or low, the degree of 'noisiness' was the lowest.

\section{Concluding Remarks}

Alongside with the increased interest in the last decade in assessing fiscal vulnerability, this paper brings its contribution by proposing a new framework, namely $V-L-D$, to measure fiscal vulnerability. $V-L-D$ comprises only two indicators: one indicator of level measuring vulnerability captured through the size of the cyclically adjusted balance and through distance-to-stability; one indicator of dynamic quantifying the vulnerability denoted by the changes in the cyclically adjusted balance and in the public debt-to-GDP ratios over two consecutive years. In order to establish relevant thresholds for our fiscal variables, we analyzed their size and changes around episodes of fiscal adjustments over a time frame ranging from 1990 to 2013. In the end, our methodology is able to assess and classify fiscal vulnerability into five categories from non-vulnerability to extreme fiscal vulnerability.

$V-L-D$ is a deterministic technique, and with its help, one can assess fiscal vulnerability at the end of the budgetary year. If forecasted data on fiscal variables employed in our methodology is available, one can estimate the degree of fiscal vulnerability for the years to come. If fiscal vulnerability needs to be measured within one budgetary year, $V-L-D$ can be tailored for monthly or quarterly data. We can also measure fiscal vulnerability over a specific time range using past data or forecasted data. $V-L-D$ is easy to be implemented in further research as it relies on data that is publicly available. It is also a very adjustable methodology for the reason that it can be customized for higher frequency data depending on the research purposes.

We employed our methodology for 28 European Union countries and found that since 2007, the Union had to tackle the largest magnitude of fiscal vulnerability, which almost doubled compared to the years before. We computed several indicators to measure fiscal vulnerability over a specific period: the total fiscal vulnerability score, the number of fiscal vulnerability episodes, and the weighted average fiscal vulnerability. We used the quartiles of each indicator to evaluate the most and the least vulnerable countries in the European Union. We found that the Czech Republic, Greece, France, Italy, Malta, Portugal, and the United Kingdom recorded the largest scores of total fiscal vulnerability over 1990 and 2013. The United Kingdom and Greece had the longest episodes of fiscal vulnerability, totaling 12 and, respectively, 11 consecutive years. Spain, Ireland, Cyprus, Romania, and Slovakia had the highest weighted average fiscal vulnerability.

In order to investigate, verify, and validate the quality of our methodology, we used the Excessive deficit Procedure to test against. We analyzed the data over 2002-2013 for 25 EU countries and found that the overall performance of $V-L-D$ is good in the sense that our framework evaluated correctly fiscal vulnerability for countries under the procedure. When we examined the methodology's effectiveness for each category based on the 'noisiness' ratio, we observed that during EDP, $V$ - $L-D$ assessed well the moderate fiscal vulnerability; in the first year during which EDP was initiated, our framework measured well the strong fiscal vulnerability; one year before the EDP was introduced, the methodology 
evaluated well the extreme fiscal vulnerability. Based on these results, we can conclude that $V-L-D$ represents a powerful tool to assess fiscal vulnerability in the European Union.

Supplementary Materials: The following are available online at http:/ / www.mdpi.com/2071-1050/10/7/2482 /s1, Appendix. Distance-to-Stability (D-S); Table S1. Fiscal adjustments episodes, 1990-2013; Table S2. Episodes of fiscal vulnerability, 1990-2013; Table S3. Total fiscal vulnerability score and the number of years of fiscal vulnerability, 1990-2013; Table S4. The length of the longest fiscal vulnerability episodes, TFVS and WAFV, 1990-2013; Table S5. Quartiles of longest fiscal vulnerability episodes, TFVS and WAFV, 1990-2013; Table S6. Ten-year fiscal vulnerability score, 2004-2013; Table S7. The excessive deficit procedure for EU countries over 2002-2013; Table S8. Testing the $V-L-D$ performance against the excessive deficit procedure; Table S9. Testing V-L-D's performance at the beginning of an EDP; Table S10. Testing $V$ - $L$ - $D$ 's performance one year before the beginning of an EDP (DOCX).

Author Contributions: Conceptualization: A.S., L.O.B., I.V.B. and B.D.; Data curation: A.S., L.O.B., I.V.B. and B.D.; Formal analysis: A.S., L.O.B., I.V.B. and B.D.; Funding acquisition: A.S.; Methodology: A.S., L.O.B., I.V.B. and B.D.; Project administration: A.S.; Resources: A.S.; Software: A.S.; Supervision: A.S.; Validation: A.S., L.O.B., I.V.B. and B.D.; Visualization: A.S., L.O.B., I.V.B. and B.D.; Writing-original draft: A.S., L.O.B., I.V.B. and B.D.; Writing-review and editing: A.S., L.O.B., I.V.B. and B.D.

Funding: This research was supported by a grant from the CERGE-EI Foundation under a program of the Global Development Network. All opinions expressed are those of the author(s) and have not been endorsed by CERGE-EI or the GDN. Grant number: RRC 14-12. https:/ / www.cerge-ei.cz.

Acknowledgments: The authors are grateful for helpful comments and suggestions made by the anonymous referees, as well as by Ira Gang (Rutgers University), Randall Filer (Charles University in Prague) and by the participants at 14th GDN/CERGE-EI Regional Research Competition Workshop, 17-18 August 2014, Prague, Czech Republic.

Conflicts of Interest: The authors declare no conflict of interest.

\section{References}

1. Confronting Budget Deficits; International Monetary Fund: Washington, DC, USA, 1996; Economic Issue 3.

2. Adema, W.; Fron, P.; Ladaique, M. Is the European Welfare State Really More Expensive? Indicators on Social Spending, 1980-2012; and a Manual to the OECD Social Expenditure Database (SOCX); OECD Social, Employment and Migration Working Papers; OECD Publishing: Paris, France, 2011; No. 124.

3. Corsetti, G.; Roubini, N. European versus American Perspectives on Balanced Budget-Rules. Am. Econ. Rev. 1996, 2, 408-413.

4. Alesina, A. The Political Economy of the Budget Surplus in the United States. J. Econ. Perspect. 2000, 14, 3-19. [CrossRef]

5. Tanzi, V.; Schuknecht, L. Reconsidering the Fiscal Role of Government: The International Perspective. Am. Econ. Rev. 1997, 87, 164-168.

6. Ghosh, A.; Kim, J.; Mendoza, E.; Ostry, J.; Qureshi, M. Fiscal Fatigue, Fiscal Space and Debt Sustainability in Advanced Economies; NBER Working Paper; National Bureau of Economic Research: Cambridge, MA, USA, 2011; No. 16782.

7. Reinhart, C.; Rogoff, K. A Decade of Debt; NBER Working Paper; National Bureau of Economic Research: Cambridge, MA, USA, 2011; No. 16827.

8. Claeys, P. Sustainability of EU Fiscal Policies: A Panel Test; IREA Working Papers 200702; University of Barcelona Institut de Recerca en Economia Aplicada: Barcelona, Spain, 2007.

9. Fatas, A.; Mihov, I. The Euro and Fiscal Policy; NBER Working Paper; National Bureau of Economic Research: Cambridge, MA, USA, 2009; No. 14722.

10. Afonso, A.; Agnello, L.; Furceri, D.; Sousa, R. Assessing Long Term Fiscal Developments: A New Approach. European Central Bank, Working Paper Series. J. Int. Money Financ. 2011, 30, 130-146. [CrossRef]

11. Hemming, R.; Kell, M.; Schimmelpfennig, A. Fiscal Vulnerability and Financial Crisis in Emerging Market Economies; IMF Ocasional Paper; IMF: Washington, DC, USA, 2003.

12. Stiglitz, J.E. Monetary Mystification, Project Syndicate. 2012. Available online: http://www.project-syndicat e.org/commentary/quantitative-easing-3--qe3--and-the-problems-of-the-fed-and-ecb-s-expansionarymonetary-policy-by-joseph-e--stiglitz (accessed on 2 October 2012). 
13. Pisani-Ferry, J. Should Europe Emulate the US? Project Syndicate, 2012. Available online: http:/ / www.project-syndicate.org/commentary/why-america-s-economy-is-recovering-faster-th an-europe-s-by-jean-pisani-ferry (accessed on 23 November 2012).

14. European Commission. The Stability and Growth Pact; European Commission: Brussels, Belgium, 2005.

15. European Commission. The European Semester; European Commission: Brussels, Belgium, 2011.

16. European Commission. Six-Pack; European Commission: Brussels, Belgium, 2011.

17. European Commission. The Treaty on Stability, Coordination and Governance in the Economic and Monetary Union; European Commission: Brussels, Belgium, 2012.

18. European Commission. Two-Pack; European Commission: Brussels, Belgium, 2013.

19. Hemming, R.; Petrie, M. A Framework for Assessing Fiscal Vulnerability; IMF Working Paper; IMF: Washington, DC, USA, 2000; WP/00/52.

20. Rial, I.; Vicente, L. Fiscal Sustainability and Vulnerability in a Small Open Economy: The Uruguayan Experience; Banca D'Italia: Rome, Italy, 2004.

21. Ghezzi, P.; Keller, C.; Wynne, J. Our Measure of Fiscal Vulnerability: A Systematic Global Approach; Barclays Capital Economic Research: London, UK, 2010.

22. Baldacci, E.; McHugh, J.; Petrova, I. Measuring Fiscal Vulnerability and Fiscal Stress: A Proposed Set of Indicators; IMF Working Paper; IMF: Washington, DC, USA, 2011; WP/11/94.

23. Baldacci, E.; Petrova, I.; Belhocine, N.; Dobrescu, G.; Maazrani, S. Assessing Fiscal Stress; IMF Working Paper; IMF: Washington, DC, USA, 2011; WP/11/100.

24. BlackRock Investment Institute. Introducing the BlackRock Sovereign Risk Index: A More Comprehensive View of Credit Quality; BlackRock Investment Institute: New York, NY, USA, 2011.

25. Hayes, S. Fiscal vulnerability: A Stocktake. In The IFS Green Budget: February 2011; Institute for Fiscal Studies: London, UK, 2011.

26. Arbatli, E.C.; Alper, E.; Jonas, J.; Weber, A.; Gerard, M.; Kinda, T.; Callegari, G.; Shabunina, A.; Schaechter, A.; Caceres, C. A Toolkit to Assessing the Fiscal Vulnerabilities and Risks in the Advanced Economies; IMF Working Paper; IMF: Washington, DC, USA, 2012; WP/12/11.

27. Berti, K.; Salto, M.; Lequien, M. An Early-Detection Index of Fiscal Stress for EU Countries; Economic Papers; European Commission: Brussels, Belgium, 2012; No. 475.

28. Furman, J.; Stiglitz, J. Economic Crisis: Evidence and Insights from East Asia; Brookings Papers on Economic Activity; William, B., Goerge, P., Eds.; The Brookings Institution: Washington, DC, USA, 1999; pp. 5-6.

29. Brixi, P.; Shatalov, S.; Zlaoui, L. Managing Fiscal Risk in Bulgaria; Policy Research Working Paper; The World Bank: Washington, DC, USA, 2000; No. 2282.

30. Detragiache, E.; Spilimbergo, A. Crises and Liquidity: Evidence and Interpretation; IMF Working Paper; IMF: Washington, DC, USA, 2001; WP/01/2.

31. Allen, M.; Rosenberg, C.; Keller, C.; Setser, B.; Roubini, N. A Balance Sheet Approach to Financial Crisis; IMF Working Paper; IMF: Washington, DC, USA, 2002; WP/02/210.

32. Daniel, J.; Davis, J.; Fouad, M.; Van Rijckeghem, C. Fiscal Adjustments for Stability and Growth; Pamphlet Series; International Monetary Fund: Washington, DC, USA, 2006; No. 55.

33. Bruglio, L.; Cordina, G.; Farrugia, N.; Vella, S. Economic Vulnerability and Resilience. Concepts and Measurements; Research Paper; UNU-WIDER: Helsinki, Finland, 2008; No. 55.

34. Aizenman, J.; Pasricha, G. Fiscal Fragility: What the Past Say about the Future; NBER Working Paper; National Bureau of Economic Research: Cambridge, MA, USA, 2010; No. 16478.

35. Frankel, J.; Saravelos, G. Are Leading Indicators of Financial Crisis Useful for Assessing Country Vulnerability? Evidence from 2008-09 Global Crisis; NBER Working Paper; National Bureau of Economic Research: Cambridge, MA, USA, 2010; No. 16047.

36. Greene, J.E. Public Finance: An International Perspective; World Scientific Publishing Company: Singapore, 2011.

37. Leiner-Killinger, N. Fiscal Vulnerabilities in the CESEE Countries: The Role of Fiscal Policy Structures and Budgetary Discipline. In Proceedings of the OeNB Workshops, 2011; No. 17, pp. 61-77. Available online: http: / / citeseerx.ist.psu.edu/viewdoc/download?doi=10.1.1.225.8954\&rep=rep1\&type=pdf\#page=61 (accessed on 10 July 2018).

38. Jedrzejowicz, T.; Kozinski, W. A Framework for Fiscal Vulnerability Assessment and Its Application to Poland; Bank for International Settlements: Basel, Switzerland, 2012; Volume 67, pp. 285-294. 
39. Missale, A. Sovereign Debt Management and Fiscal Vulnerabilities; Bank for International Settlements: Basel, Switzerland, 2012; Volume 65, pp. 157-176.

40. Cottarelli, C. The Risk Octogon: A Comprehensive Framework for Assessing Sovereign Risks. Paper Presented at Seminar Held at the Sapienza University, Rome, Italy, 25 January 2011; Politeia: London, UK, 2011.

41. Bouthevillain, C.; Quinet, A. The Relevance of Cyclically-Adjusted Public Balance Indicators-The French Case in Indicators of Structural Balance; Banca d'Italia: Rome, Italy, 1999.

42. Alesina, A.; Ardagna, S. Tales of Fiscal Adjustment. Econ. Policy 1998, 13, 489-585. [CrossRef]

43. AMECO Database. Available online: https://ec.europa.eu/info/business-economy-euro/indicators-statist ics/economic-databases/macro-economic-database-ameco/ameco-database_en (accessed on 31 July 2014).

44. Kaminsky, G.; Lizondo, S.; Reinhart, C. Leading Indicators of Currency Crises; IMF Staff Papers; IMF: Washington, DC, USA, 1998; Volume 45, pp. 1-48, No. 1.

(C) 2018 by the authors. Licensee MDPI, Basel, Switzerland. This article is an open access article distributed under the terms and conditions of the Creative Commons Attribution (CC BY) license (http://creativecommons.org/licenses/by/4.0/). 